\title{
Opportunity and rationality as an explanation for suspicious vehicle fires: demonstrating the relevance of time, place, and economic factors
}

\author{
Hannah Kelly ${ }^{1}$, Joseph Clare $2^{2^{*}}$, Kathryn Wuschke ${ }^{3}$ and Len Garis ${ }^{4}$
}

\begin{abstract}
Opportunity theories of crime emphasize the non-random spatial and temporal patterning of criminal events. Such theoretical development has proven useful when extended beyond traditional applications to crime event data. This study continues to explore the wider utility of such criminological theories by examining the spatio-temporal patterns of vehicle fires through an opportunity lens. Specifically, we explore the patterns associated with different types of vehicle fires, and consider longitudinal socio-economic trends that may influence the perceived costs and benefits associated with crimes committed with the intention of escaping debt, such as vehicle arson. Data for this study were obtained from Surrey Fire Services (2000-2015) and contain information about all vehicle fires occurring in Surrey, British Columbia (BC), Canada. Post-fire incident reports were used to group the fire data into non-suspicious and suspicious categories. Both categories were analyzed for local and global spatial clustering, hourly, daily, and monthly temporal patterns, and changes over the study period. Findings indicate that suspicious vehicle fire events concentrate in both space and time, and these patterns are distinct from non-suspicious vehicle fires. Further, suspicious vehicle fires events are significantly related to unemployment and interest rates, whilst non-suspicious vehicle fires are not. These results demonstrate the relevance of opportunity theories of crime to understanding vehicle fire patterns. By extension, this provides an important opportunity to connect such patterns with targeted crime (and fire) prevention policy and practice.
\end{abstract}

Keywords: Vehicle fires, Rational choice, Arson, Crime prevention, Opportunity theory

\section{Introduction}

Recent research indicates that the trends and patterns of fire events can be usefully explored through theoretical lenses developed and applied within criminology (e.g., Clare et al. 2012, 2017; Corcoran et al. 2010, 2011; Grubb and Nobles 2016; Turchan et al. 2018; Wuschke et al. 2013). This paper contributes to the body of literature exploring the spatial and temporal distribution of fire events by examining vehicle fire patterns through an opportunity theory lens. It further incorporates local

\footnotetext{
*Correspondence: joe.clare@uwa.edu.au

${ }^{2}$ The University of Western Australia, M253, 35 Stirling Highway, Perth, WA 6009, Australia

Full list of author information is available at the end of the article
}

economic indicators related to individual financial strain and varying capacity to repay debt. We begin with an overview of established empirical crime patterns that lend themselves to an opportunity-based explanation. The relevance of these theories are extended to what is known about arson, followed by a review of the relationship between economic indicators and vehicle arson. We then add novel contributions to the literature by analyzing the spatial and temporal patterns associated with non-suspicious and suspicious vehicle fires (as defined by the fire service), followed by a longitudinal analysis of the relationship between economic indicators associated with financial strain, and the frequency of these two types of fire. The findings demonstrate clear differences between non-suspicious and suspicious vehicle fires, with 
the latter patterned in a manner that can be explained by opportunity and rationality (in the form of arson to escape debt). These results are discussed in terms of the contribution they make to theory and practice. This research provides an additional contemporary example of the benefits of applying opportunity-based criminological theory to first responder problems that extend beyond the traditional criminal justice players.

\section{Crime as rational opportunity}

Crime is non-randomly distributed across space, as frequently emphasized within existing literature (e.g., Ackerman and Murray 2004; Eck 2015; Groff and McCord 2012; Harries 2006; Kinney et al. 2008; Weisburd 2015). Further, crime events are non-randomly distributed across time, clustering at predictable times of the day (e.g., Cohen and Felson 1979; Ratcliffe 2002), days of the week (e.g., Felson and Poulsen 2003), and throughout the year (e.g., Andresen and Malleson 2013; Cohn and Rotton 2000; Haberman et al. 2017; Landau and Fridman 1993; Newton and Felson 2015; Perry and Simpson 1987). There is also a non-random involvement of people as both offenders (e.g., Martinez et al. 2017) and victims (e.g., SooHyun et al. 2017). These high-level crime patterns hold true when focusing specifically on emergency responses to fires (Clare et al. 2017; Corcoran et al. 2010, 2011; Wuschke et al. 2013) and, in particular, within arson events (Asgary et al. 2010; Grubb and Nobles 2016; Potter 2000). Spatio-temporal patterns of arson reveal a higher amount of incidents occurring at night, over the weekend, and in areas with little surveillance (Asgary et al. 2010; Grubb and Nobles, 2016; Potter 2000). Arson also demonstrates near-repeat clustering (Grubb and Nobles 2016; Turchan et al. 2018) typically observed within other crime types (Bernasco 2008; Johnson 2008; Townsley et al. 2003; Powell et al. 2019).

Three main theoretical perspectives combine to help explain these non-random patterns. First, routine activity theory (Cohen and Felson 1979) describes crime as normal, occurring as a byproduct of the daily routines of urban residents in modern society that produce regular patterns of movement and activity. According to routine activity theory, when there is a spatio-temporal convergence of a motivated offender and a suitable target in the absence of a capable guardian, the opportunity for a crime is created. Next, crime pattern theory (Brantingham and Brantingham 1991, 1993, 2008) explains how the physical urban form and the individual's cognitive awareness space (that develops as a consequence of their normal movement patterns) influence the distribution of criminal events across time and space. Finally, the rational choice perspective (Cornish and Clarke 2008) explains how the decision to offend is mediated by context, with offenders making crime-specific 'rational' choices, 'bounded' by factors such as time, cognitive ability, and available information, with these decisions influenced by the immediate perceptions of risk, reward, and effort for the actions. This perspective argues that offending decisions are influenced by the risks/rewards posed by the immediate situation (as opposed to the longerterm consequences of apprehension). The rational choice perspective has been extended to present crime events as scripts, with factors that occur before, during, and after crime playing an important role in influencing the perceived rationality of the offending action (see Leclerc 2017, for a summary of the literature relating to crime scripts and rational choice). Offending decisions vary at each stage within the script, as well as between potential offenders.

\section{Rationality, the economy, and arson}

The common elements within routine activity theory, crime pattern theory, and the rational choice perspective are the importance they place on opportunity, space, and time, as well as the context-specific nature of rationality. A crucial contribution of rational choice to explaining offending is the assumption that crime decisions can be made by anyone (regardless of previous offending patterns) provided they perceive the immediate contextual rewards to outweigh the risks/effort involved. Events such as sudden unemployment or unexpected interest rate hikes, for example, can leave one unable to manage their personal debt, resulting in substantial levels of stress. Economic factors, then, have the potential to influence otherwise law-abiding people to perceive crimes, such as arson, as rational.

Financial stress can lead individuals to go to extreme lengths to escape these strains, as demonstrated by increases in both crime and suicide during times of economic downturn (Milner et al. 2015; United Nations Office on Drugs and Crime 2011). Focusing specifically on fire, research has found that both arson and insurance fraud are influenced by economic factors (Dionne and Wang 2013; Eriksen and Carson 2017). For example, Goebel and Harrison (2012) demonstrate that residential arson significantly increases in areas with high rates of housing foreclosure and unemployment. Eriksen and Carson (2017) extend these results by documenting that as that housing price declines, the prevalence of arson and the likelihood of arson-related insurance fraud increase. Further, the authors find a stronger, negative correlation between home price and arson in states that allow lenders to litigate homeowner foreclosures (Eriksen and Carson 2017). A drop in housing prices, combined with an increased potential for legal repercussions associated with loan foreclosure may shift the risk/reward 
ratio to make arson a rational choice during times of economic instability.

The link between arson, opportunity, and the economy also extends to vehicle fires, with Dionne and Wang (2013) demonstrating motor vehicle theft insurance fraud increases during times of recession (also see United States Fire Administration 2014). Furthermore, through analysis of police and fire data relating to vehicle fires, Merrall and Chenery (2005) found a strong, positive correlation between motor vehicle theft and vehicle arson, with over $50 \%$ of the deliberate primary vehicle fires in their study occurring in vehicles that had been reported stolen. Merrall and Chenery (2005) also undertook a series of interviews with arson offenders and found that, in addition to burning stolen vehicles to remove forensic evidence, "over half of the offenders interviewed said they had been approached to commit vehicle arson on behalf of a third party, with just under half saying that they had actually committed vehicle arson on behalf of the vehicle's current keeper for payment of between $£ 50$ and $£ 100$ " (Merrall and Chenery 2005, p. 15, point 41). This scenario describes the deliberate removal of the guardian, to allow the motivated offender access to the target. Similarly, Potter (2000) and Devery et al. (1993) compared the characteristics of stolen vehicles subject to arson and those that were recovered undamaged, finding a number of reasons to indicate that many of the vehicles recovered burnt may have involved insurance fraud. Relating such events back to the non-random, rational, opportunitybased patterns discussed above, Potter (2000) found that suspected fraudulent fires: (a) occurred in vehicles that had been stripped of valuables; (b) involved significantly newer and more expensive cars; (c) were more likely to occur at night and over weekends; (d) more frequently involved cars that were stolen from residential addresses (as opposed to streets and car parks); and (e) more frequently involved vehicles with agreed (as opposed to market) value insurance policies, meaning their level of cover likely exceeded the price they could achieve through legitimate sale.

\section{Aim and hypotheses}

Building on the findings related to opportunity theories of crime and the relationship between crime, the economy, and vehicle arson, the aim of this research is to examine non-suspicious and suspicious vehicle fires by comparing the spatio-temporal patterns and the relationship with local economic indicators associated with increased individual financial stress and varying capacity to repay debt. The following hypotheses will be tested:

$H_{1}$ : Non-suspicious vehicle fires will demonstrate spatio-temporal patterns consistent with typical, routine vehicle usage.
$\mathrm{H}_{2}$ : Suspicious vehicle fires will demonstrate atypical, non-routine spatio-temporal vehicle usage patterns.

$H_{3}$ : Non-suspicious vehicle fires will not demonstrate a significant relationship with economic indicators related to increased individual financial stress.

$H_{4}$ : Suspicious vehicle fires will demonstrate a positive relationship with economic indicators related to increased individual financial stress.

\section{Methodology \\ Study area}

Surrey, British Columbia (BC), is the largest suburb (121.5 square miles) within Metropolitan Vancouver, and is located approximately 17 miles east of Vancouver. Canada's 2016 Census reported Surrey's population as slightly in excess of 500,000, making it the second largest city within BC, and the twelfth largest in Canada (Statistics Canada 2017). The city is bordered on the north by the Fraser River and on the south by the United States. Zoning is highly varied throughout the city, with nearly half of the urban area zoned in one of three residential categories (22.6\% Single Family; 20.1\% Low Density; 4.1\% High Density), along with a considerable expanse of agricultural and open zones (33.3\%). Commercial zones, including public halls, account for $4.5 \%$ of the city, with the remaining land area designated as industrial (8.4\%) and as comprehensive development zones (6.9\%), which facilitate the development of mixed land use centers (see Fig. 1 for zoning and road network details).

\section{Vehicle fire data}

Time series data containing information on all vehicle fires that occurred in Surrey from 2000 to 2015 $(n=4121)$ were obtained from Surrey Fire Services. The data was originally collected by qualified fire inspectors from Surrey Fire Services as administrative data, following post-fire inspections of burned vehicles. This is routine practice when responding to and investigating fire incidents. The term 'vehicle fire' includes any fire that occurred in or involved a motorized vehicle (such as cars, boats, buses, campervans, motorbikes, etc., including structural fires that involved a vehicle). Details regarding the suspected 'act or omission' that caused the fire, as well as the location and time of the fire incident were included in the dataset.

The vehicle fire data were cleaned, geocoded, and separated into two groups (non-suspicious and suspicious vehicle fires). Groups were determined by the 'act or omission' believed to have had caused each fire, as determined by the fire inspector and recorded in the data. As vehicles contain fuel, when set alight they burn at a high intensity and as a result, burn out completely and very quickly, resulting in the cause of the fire being cited as 


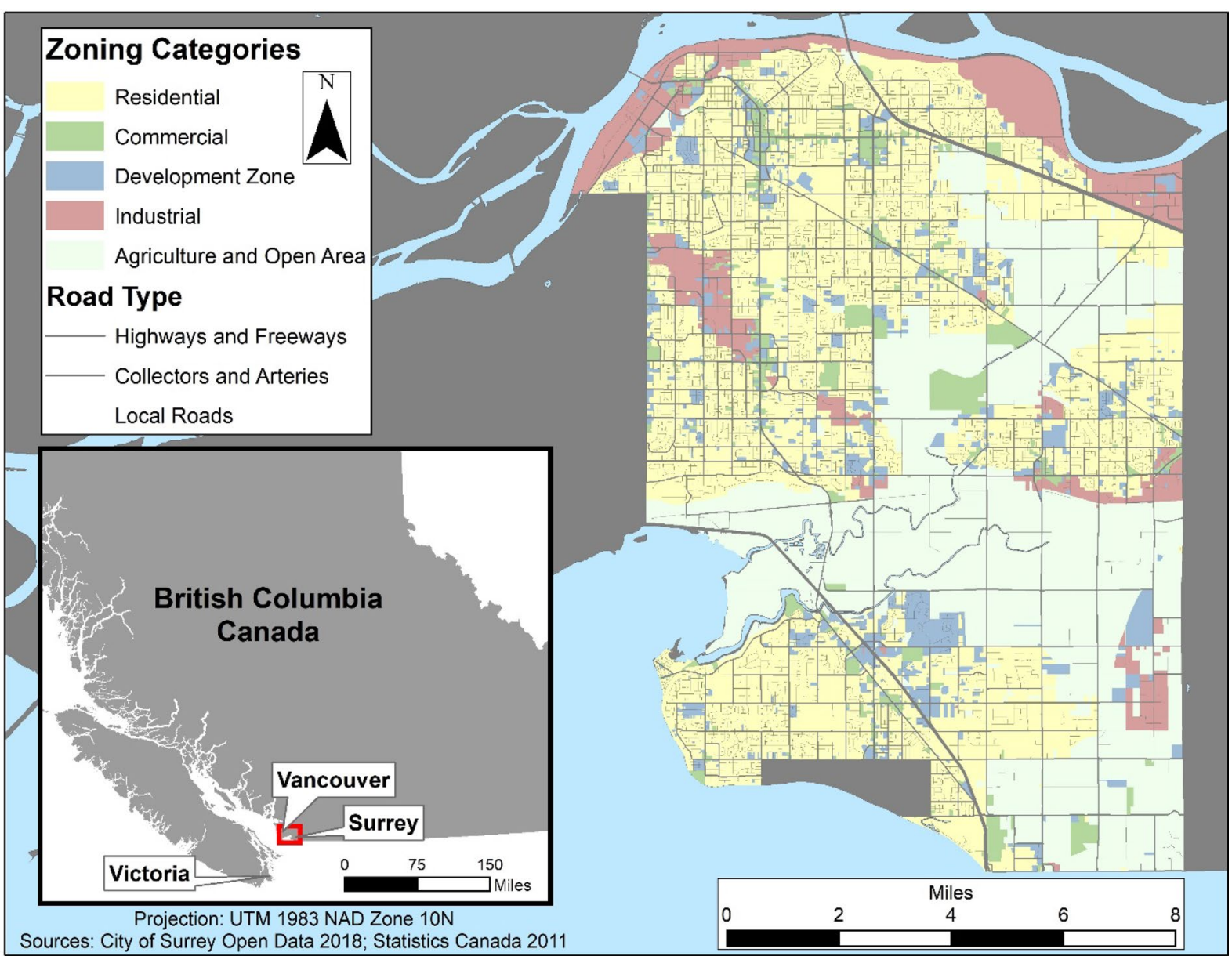

Fig. 1 Surrey, BC: Location, zoning and road type

'unknown' in many cases. In total, 2214 events where the 'act or omissions' could not be determined were removed from the data and a further two records were removed due to missing classification data or spatial references. This left a final sample of 1905 fires: 1315 (69.0\%) were recorded as suspicious as a result of a suspicious incendiary event, while the remaining 590 events were deemed to be non-suspicious events. ${ }^{1}$

Once the fire groups were established, each fire occurrence was mapped based on the spatial coordinates to the event itself. Fire events were then aggregated to the 2011 Canadian Census dissemination area (DA) in which

\footnotetext{
${ }^{1}$ The various combination of act/omission across these non-suspicious fires was mechanical/electrical failure $(n=432)$, human failing $(n=69)$, vehicle accident $(n=29)$, misuse of ignition $(n=27)$, misuse of materials ignited $(\mathrm{n}=20)$, miscellaneous $(\mathrm{n}=8)$, construction/design/installation deficiency $(\mathrm{n}=3)$, and misuse of equipment $(\mathrm{n}=2)$. While all classifications are performed by qualified fire inspectors, the data does not provide insight into who classified the data, or what specific decision-making criteria was used to determine the classification.
}

they occurred, resulting in a count of suspicious and nonsuspicious events within each DA (as per Wuschke et al. 2013). DAs are the smallest geographic area to which all census information is aggregated in Canada (Statistics Canada 2015). These areas are designed to remain consistent from census to census, and typically contain 400 to 700 residents (Statistics Canada 2015). In 2011, the City of Surrey was divided into 592 DAs. Following aggregation, ten fire events within the dataset were associated with locations outside of the City of Surrey itself, and were thus excluded from the spatial analysis portion of this study. These included 8 non-suspicious events, and 2 suspicious events.

\section{Economic indicators}

When examining the relationship between the economy and crime, in addition to analyzing unemployment (e.g., Chiricos 1987), Andresen (2013) recommended considering indicators such as wages/salaries, gross domestic product/gross state product, the index of consumer 
sentiment, inflation, and interest rates, to minimize the risk of 'omitted variable bias'. A number of recent studies have demonstrated the significant relationship between these varied economic indicators and crime rates (e.g., Andresen 2013; Jones and Kutan 2004; Rosenfeld and Fornango 2007; Seals and Nunley 2007; Yearwood and Koinis 2011). Given that the purpose of this study was to examine the relationship between opportunity, rationality, and local economic indicators relating to individual financial strain and varying capacity to repay debt, BC unemployment and Canadian interest rates were selected as economic indicators appropriate for analysis. As emphasized by Eriksen and Carson (2017), increases in economic strain (as may be associated with increasing unemployment and interest rates) could provide sufficient incentive to commit arson as a means of escaping debt; this echoes the risk/reward balance offered within the rational choice perspective.

\section{Unemployment}

The unemployment rate estimate is collected as part of the Canadian Labour Force Survey (Statistics Canada 2019b). The labor force consists of all individuals 15 years and over who, at the time of the census, were considered employed or unemployed, as per the definitions provided in the survey. Unemployment is measured as the number of people who were without work but had been actively seeking work within four weeks of the survey reference week (Statistics Canada 2019b). The unemployment rate is calculated as the number of unemployed people expressed as a percentage of the labor force. This study utilized monthly estimates for unemployment figures specific to $\mathrm{BC}$.

\section{Interest rates}

Historical trends in interest rates in Canada are made available as part of the Canadian Socio-Economic Information Management system (CANSIM, Statistics Canada 2019a). Monthly interest rate values were collected from the CANSIM portal for use in this study.

\section{Results}

\section{Spatio-temporal comparison of non-suspicious and suspicious vehicle fires}

Initially, hot spot analysis were conducted for both nonsuspicious and suspicious fire groups in order to identify within-group variation in concentration. Fire counts were used because identifying locations with high numbers of fire events is of operational value for resource allocation purposes (Andresen et al. 2009; Simpson 1996). The Global Moran's $I$ values indicated that both fire groups were significantly spatially clustered at the DA-level (non-suspicious fires: Moran's $I=0.03 ; Z=3.32 ; p<0.05$; suspicious fires: Moran's $I=0.04 ; Z=4.75 ; p<0.05$ ). However, as can be seen from Fig. 2, there was substantial overlap in the local-level hot and cold spots for both non-suspicious and suspicious fires $\left(\mathrm{Gi}^{*} Z\right.$-score value greater than |1.96|).

To further explore $H_{1}$ and $H_{2}$, Andresen's (2016) spatial point pattern test was used. The spatial point pattern test produces both a global Index of Similarity $(S)$, which identifies whether the two data sets are similar or different, as well as a local measure to identify how these differences vary between sub-areas. Global S-Index values near 0 are considered to be dissimilar, while those nearing 1 are similar. While there is no statistically significant threshold to indicate (dis)similarity, research applying Andresen's test frequently use 0.8 as an indicator: above this level, the two spatial point patterns can be considered similar (Andresen 2016). Both non-suspicious and suspicious vehicle fire events significantly and uniquely cluster within Surrey's DAs. At the global level, the $S$-value is 0.51 (100 iterations, $85 \%$ sample size, $95 \%$ confidence interval), indicating that the non-suspicious and suspicious fire patterns are dissimilar. The spatial point pattern test further measures local level variations at the DA level, with results displayed in Fig. 3. DAs shaded in blue indicate a significant over-representation of nonsuspicious vehicle fires, while red-shaded DAs indicate proportionally more suspicious fire events. While variations exist across the city, DAs displaying over-representation of non-suspicious events contain major roadways, and DAs displaying over-representation of suspicious fires largely overlap with the city's agricultural and open areas, as well as the primarily industrial areas-locations that may be selected based on their lack of guardians capable of preventing the fire.

Noting that several of these areas act as hot spots (or cold spots) of both non-suspicious and suspicious fire events, the zoning category in which the event occurred was also examined. Zoning information (as visualized in Fig. 1) was joined to every fire event in order to compare the proportions of each event accordingly. These results (Table 1) indicate single family residential zones and agricultural zones had significantly more suspicious vehicle fires, whilst development and commercial zones experienced more non-suspicious vehicle fires.

The temporal fire patterns were then analyzed using directional statistics (to account for relationships in circular data distributions with no zero value, see Fig. 4). Within-group temporal trends were tested using Rayleigh's $Z$ statistic (testing for a mean vector, defined by direction $\left(\theta\right.$, ranging between $0^{\circ}$ and $\left.359^{\circ}\right)$ and length $(r$, ranging between $0=$ uniform distribution in all directions and $1=$ data concentrates in one direction)). Between-group trends were tested using Watson's $U^{2}$ test 


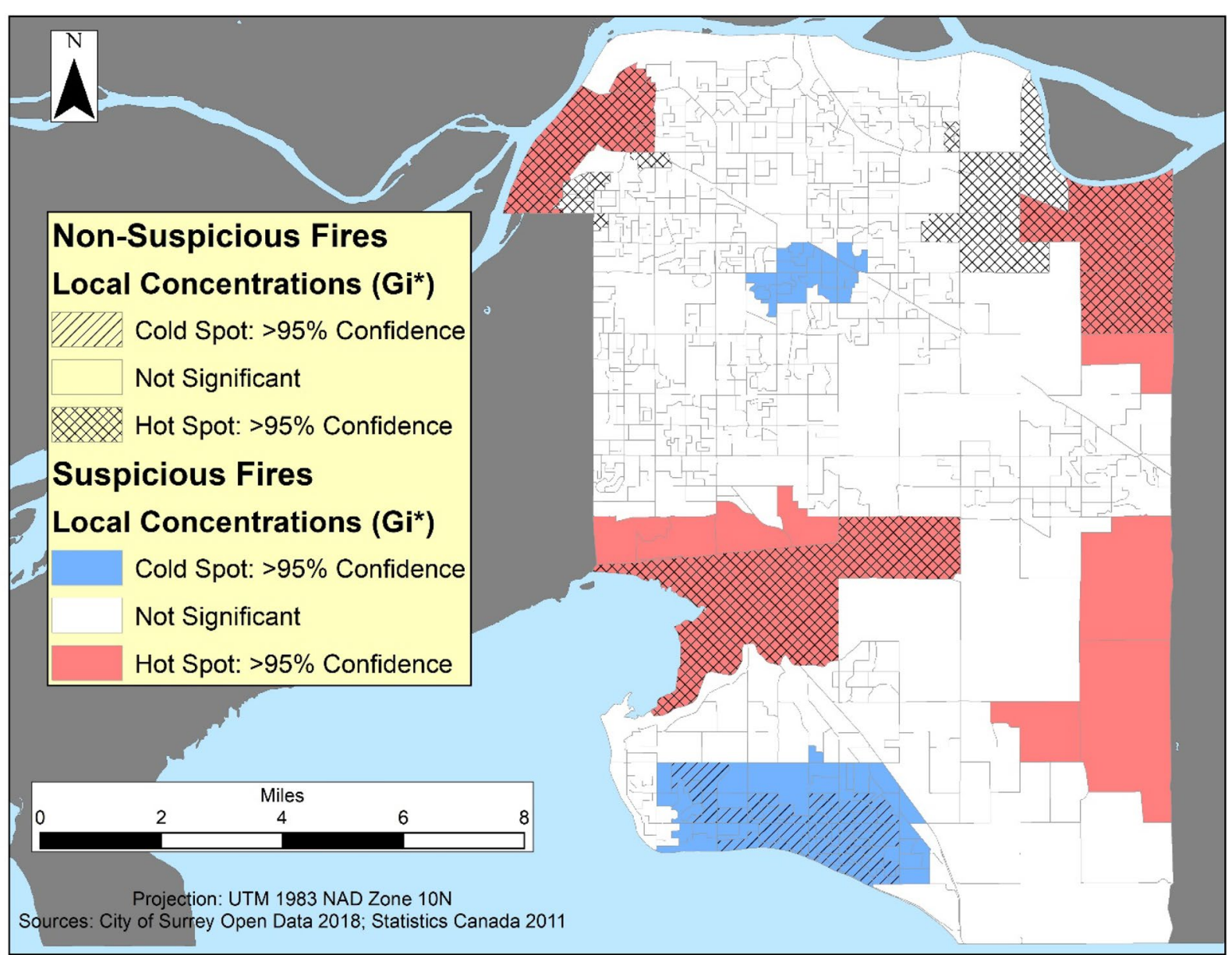

Fig. 2 Local cold spots and hot spots of non-suspicious fires (denoted by striped and cross-hashed patterns, respectively) as well as cold and hot spots of suspicious fires (blue and red shades, respectively)

for directional data, which is a non-parametric test that identifies significant differences between the mean angles of two directional datasets. Neither fire type showed a significant within-group concentration by months of the year (non-suspicious fires Rayleigh's $Z=1.35$ and suspicious fires Rayleigh's $Z=2.33$; critical value $(\mathrm{CV})$ at $0.05=3.00$ ), however, between-group comparisons revealed these two datasets were significantly different from one another at this temporal level of aggregation (Watson's $U^{2}=0.25 ; p<0.05$ ). When grouped according to the days of the week, non-suspicious fires exhibited no significant concentration (Rayleigh's $Z=1.48$ ) but suspicious fires did cluster (Rayleigh's $Z=17.37$, $p<0.05, \theta=0.56^{\circ}, r=0.12$, mean vector on Sunday at 12:16 am). Further, between-group comparisons indicated significant differences in day-of-the-week patterns between suspicious and non-suspicious events (Watson's $\left.U^{2}=14.13 ; p<0.05\right)$. When grouping data according to the hour of the day that the event was recorded, both non-suspicious $\left(Z=60.81, p<0.05, \theta=181.04^{\circ}, r=0.32\right.$, mean vector $12: 04 \mathrm{pm})$ and suspicious events $(Z=60.81$, $p<0.05, \theta=181.04^{\circ}, r=0.59$, mean vector $\left.12: 02 \mathrm{am}\right)$ exhibited significant clustering, with significant betweengroup differences (Watson's $U^{2}=14.13 ; p<0.05$ ).

Overall, these spatio-temporal findings produced results that are supportive of $H_{1}$ (non-suspicious vehicle fires demonstrating spatio-temporal patterns consistent with typical, routine vehicle usage) and $H_{2}$ (suspicious vehicle fires demonstrating spatio-temporal patterns consistent with atypical, non-routine vehicle use). At a DA-level, the spatial point pattern test demonstrated the spatial distribution of non-suspicious and suspicious fires were dissimilar. Non-suspicious fires occurred in areas containing major roadways, where high traffic flow and congestion increase potential for legitimate vehicle fires. Consistent with the expectations from a opportunity/rational choice explanation for vehicle arson, suspicious fires occurred in areas 


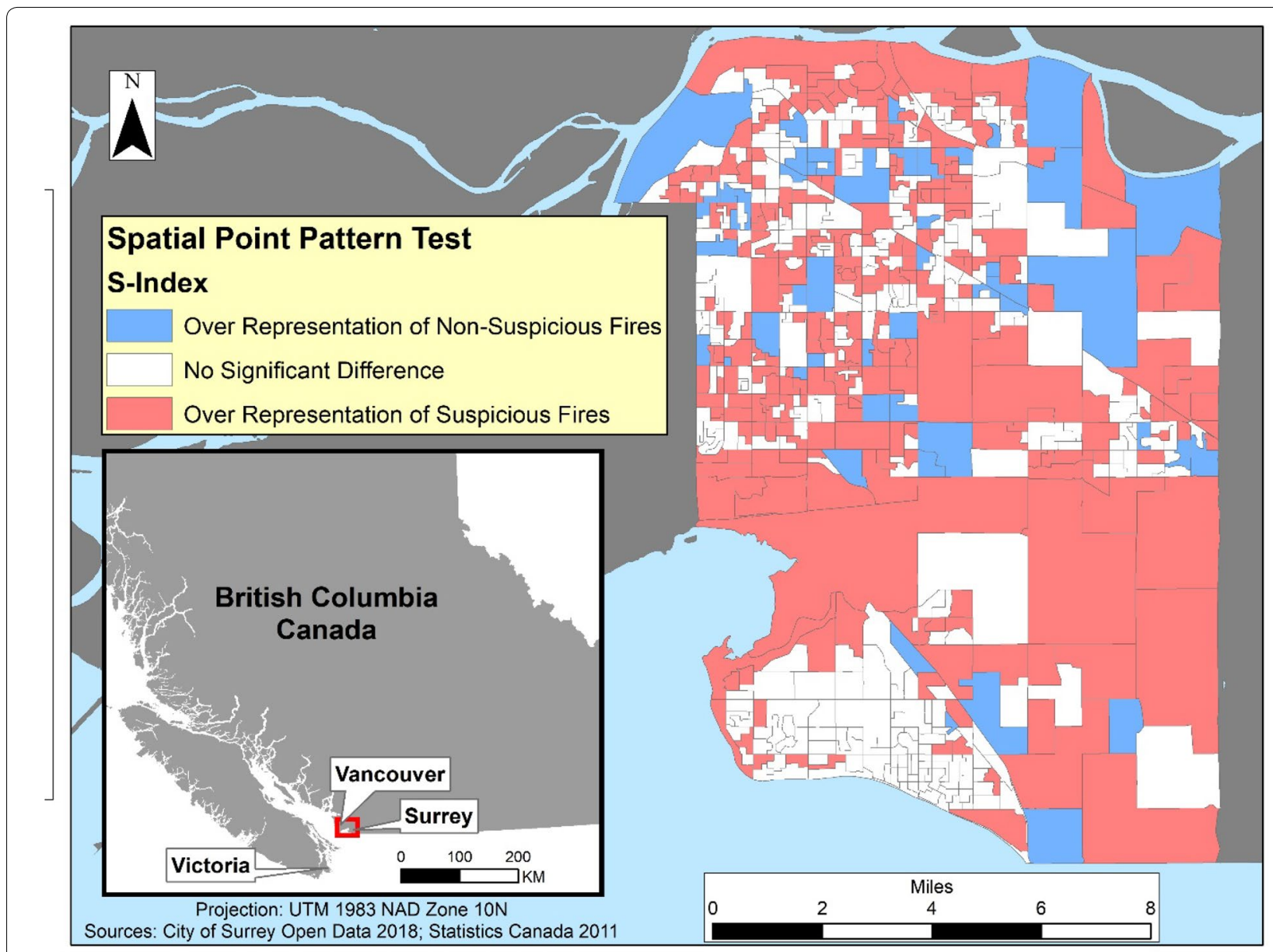

Fig. 3 Local-level comparison of the spatial patterns of non-suspicious and suspicious fires. Blue areas represent dissemination areas where non-suspicious fires are over-represented; red-shaded dissemination areas denote an over-representation of suspicious fires

Table 1 Non-suspicious and suspicious vehicle fires by zoning category: surrey, BC (2000-2015)

\begin{tabular}{|c|c|c|c|c|c|}
\hline \multirow[t]{2}{*}{ Zoning categories } & \multicolumn{2}{|c|}{$\begin{array}{l}\text { Non- } \\
\text { suspicious } \\
\text { fires }\end{array}$} & \multicolumn{2}{|c|}{ Suspicious fires } & \multirow[t]{2}{*}{ Z-Score } \\
\hline & $f$ & $\%$ & $f$ & $\%$ & \\
\hline Single family residential & 150 & 25.42 & 430 & 32.70 & $-3.13^{\mathrm{a}}$ \\
\hline Low-density residential & 105 & 17.80 & 201 & 15.29 & 1.45 \\
\hline Agriculture & 39 & 6.61 & 196 & 14.90 & $-5.76^{\mathrm{a}}$ \\
\hline Industrial & 75 & 12.71 & 169 & 12.85 & 0.01 \\
\hline Development zone & 75 & 12.71 & 120 & 9.13 & $2.34^{\mathrm{a}}$ \\
\hline High-density residential & 44 & 7.46 & 95 & 7.22 & 0.25 \\
\hline Commercial & 91 & 15.42 & 94 & 7.15 & $5.09^{\mathrm{a}}$ \\
\hline Public hall & 3 & 0.51 & 8 & 0.61 & 0.26 \\
\hline Total & 582 & & 1313 & & \\
\hline
\end{tabular}

a Indicates a statistically significant difference in Z-proportions, with negative values indicating a larger proportion in the suspicious category and vice versa for positive values where there were relatively low risks of detection from guardians/place managers and less frequent routine vehicle use (agricultural, open, and industrial areas). Temporally, non-suspicious fires did not cluster by day of the week, and peaked at times when typical, routine vehicle use would be at its highest (US Department of Transport 2009, estimated $47.2 \%$ of 2009 trips commenced between 9 am and $4 \mathrm{pm}$ ). In contrast, suspicious fires occurred more often very late at night and on the weekends, at times when guardians/place managers would likely be absent and when typical, routine vehicle use is much less frequent (US Department of Transport 2009, estimated $4.2 \%$ of 2009 trips commenced between $10 \mathrm{pm}$ and $6 \mathrm{am}$ ). The next section of the results considers the relationships between suspicious and non-suspicious vehicle fires and longitudinal trends in economic factors related to individual financial stress and varying capacity to repay debt. 


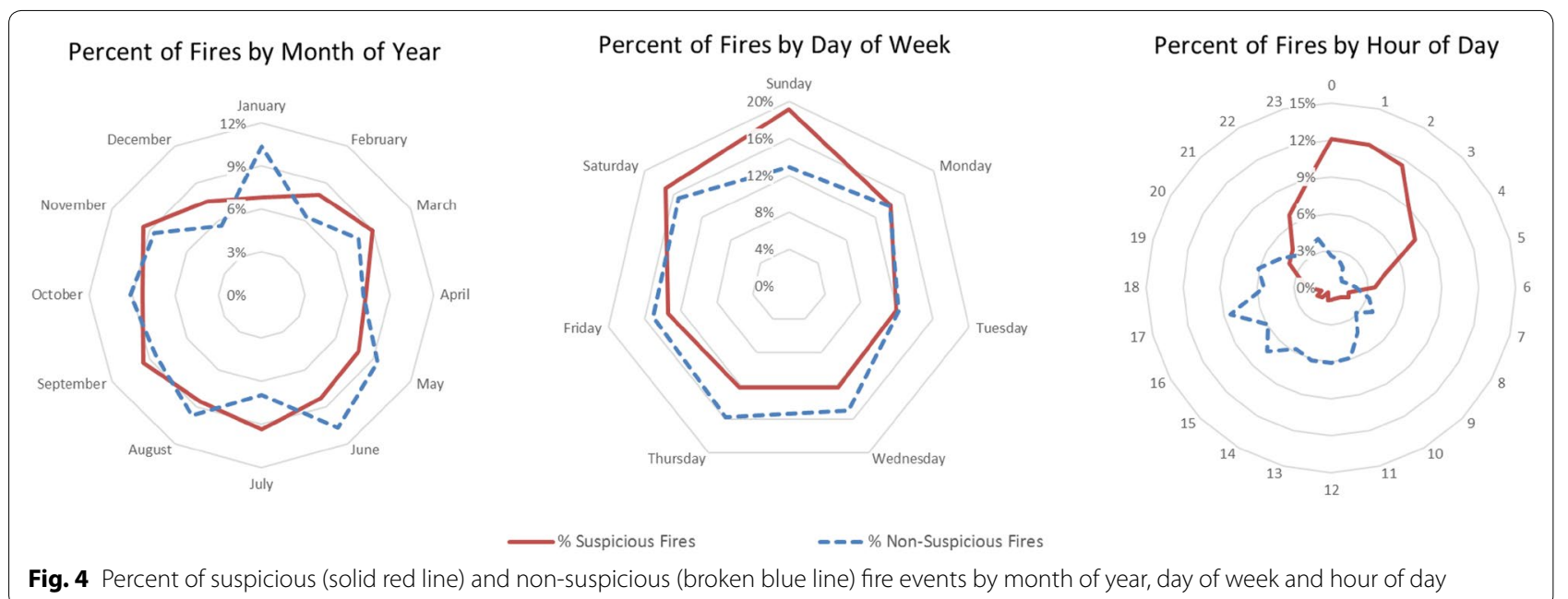

Table 2 OLS regression analysis of suspicious and nonsuspicious vehicle fires (robust standard errors)

\begin{tabular}{lllll}
\hline Fire type & Predictor & $\boldsymbol{\beta}$ & $\boldsymbol{S E}$ (robust) & $\boldsymbol{p}$ value \\
\hline Suspicious & Unemployment & 1.25 & 0.21 & $<.0001$ \\
& Interest rates & 1.18 & 0.19 & $<.0001$ \\
\multirow{2}{*}{ Non-suspicious } & Unemployment & 0.14 & 0.13 & $n \mathrm{~ns}$ \\
& Interest rates & 0.11 & 0.11 & $\mathrm{~ns}$ \\
\hline
\end{tabular}

\section{Vehicle fires and the economy}

During the period of study the average BC unemployment rate was $6.66 \%(S D=1.38, \min =3.8, \max =9.8)$ and the average interest rate was $2.55 \%(S D=1.58$, $\min =0.5, \max =6.0$ ). Consistent with prior research examining crime and the economy (Merrall and Chenery 2005; Rosenfeld and Fornango 2007; Sidebottom et al. 2011; Smith et al. 1992) the relationship between vehicle fires (both non-suspicious and suspicious) and the economic variables (unemployment and interest rates) were initially explored using an ordinary least squares (OLS) regression. Following the precedent set by Sidebottom et al. (2011) it is reasonable to assume that the influence of changes in these local economic conditions would have a lagged effect on the perceived rationality of considering vehicle arson as a way of escaping an unwanted financial situation. As such, the OLS regressions were computed using one month lag values for unemployment and interest rates. The results are presented in Table 2, showing a significant positive relationship between suspicious vehicle fires and the two economic indicators, but not for non-suspicious vehicle fires.

The Durban-Watson test revealed that for both the suspicious fires (Durban-Watson $=1.17$ ) and the nonsuspicious fires (Durban-Watson $=1.26)$, temporal
Table 3 Generalized least squares regression analysis of suspicious and non-suspicious vehicle fires (robust standard errors)

\begin{tabular}{llcll}
\hline Fire type & Predictor & $\boldsymbol{\beta}$ & $\boldsymbol{S E}$ (robust) & $\boldsymbol{p}$ value \\
\hline Suspicious & Unemployment & 0.93 & 0.30 & $<.003$ \\
& Interest rates & 1.12 & 0.29 & $<.001$ \\
& AR1 term & -0.42 & 0.07 & $<.0001$ \\
\multirow{2}{*}{ Non-suspicious } & Unemployment & 0.07 & 0.17 & $\mathrm{~ns}$ \\
& Interest rates & 0.11 & 0.16 & $\mathrm{~ns}$ \\
& AR1 term & -0.36 & 0.07 & $<.0001$ \\
\hline
\end{tabular}

autocorrelation was apparent (values significantly below 2.0 indicating temporal autocorrelation is present in the data), with significant correlations demonstrated for residuals in both models $(r=0.41$ and $r=0.35$, respectively). To ensure the bias created by temporal autocorrelation was accounted for, two separate generalized least squares regression models that adjusted for serial correlation were conducted. The results are displayed in Table 3 .

The generalized least squares models indicate that the relationships identified previously were reliable. The non-suspicious vehicle fires did not demonstrate any relationship with unemployment or interest rates (model $R^{2}=0.14$, Durban-Watson $=2.18, n s$ ). However, when considering suspicious fires, the relationships with local unemployment and interest rates were still significant and positive, indicating that increases in these economic variables was related to an increase in the frequency of suspicious vehicle fires in the following month (model $R^{2}=0.36$, Durban-Watson $=2.18, n s$ ). These results are consistent with $\mathrm{H}_{3}$ (non-suspicious vehicle fires will not demonstrate a significant relationship with economic indicators related to increased individual financial stress) 
and $H_{4}$ (suspicious vehicle fires will demonstrate a positive relationship with economic indicators related to increased individual financial stress). These patterns are consistent with a rational choice perspective account of vehicle arson, particularly with respect to the assumption that offending decisions can be made by anyone as a function of the immediate relative assessment of the rewards versus risk/effort of their actions.

\section{Discussion \\ Implications}

This research provides an additional, contemporary example of the benefits of applying opportunity-based criminological theory to first responder problems that extend beyond the traditional criminal justice players (Clare et al. 2012, 2017; Wuschke et al. 2013). Furthermore, given this clear utility of opportunity/rationality-based explanations of offending to understanding suspicious vehicle fire, this opens the door for the development of strategies to reduce the opportunity for similar fires in the future. The extension of rational choice and routine activity contributed to the development of the twenty-five techniques of situational crime prevention (e.g., see Clarke 2008, for a full history of this framework), which use five categories of actions to manipulate crime opportunities: increase effort, increase risk, reduce rewards, reduce provocations, and remove excuses. Given the geographic and temporal specificity of the suspicious fires displayed here, it is plausible that some of the twenty-five techniques could be implemented with the goal of reducing this problem at vehicle arson hotspots throughout the city. For example, working in partnership across relevant agencies (police, fire, bylaws, neighborhood watch, etc.) and focusing on some of the highest frequency time/place combinations for suspicious fires, situational crime prevention can offer a framework for identifying locally-based solutions to address the city's vehicle fire concerns. These solutions would begin with a local-level analysis within DAs identified as hotspots of suspicious fires. Approaches would be locally-informed and site-specific, and may include (a) increasing the effort for vehicle arson by controlling entry and screening exits at high-risk arson locations, (b) increasing the risk by enhancing guardianship through natural/formal surveillance and the use of place managers at high-risk locations; (c) reducing provocations by using media to discourage imitation, publicizing failed attempts at insurance fraud and increased risk in known vehicle arson hot spots; and (d) removing excuses by posting instructions/ alerting offender conscience in hot spot areas with signage about consequences for insurance fraud and risks of apprehension in those areas. Working in partnership with police and insurers, it is also possible to deny benefits for vehicle insurance fraud, by implementing mandatory investigations into suspicious fires (as determined by the place, time, circumstances surrounding the theft and fire, outstanding debt connected to the vehicle, etc.).

\section{Limitations and future directions}

There are some limitations associated with the data involved in the current study. The fires used in this research were defined as suspicious (or not) based on the post-fire inspection undertaken by the fire service. While fire inspectors must be licensed, the data does not include individual identifiers to test for inter-rater reliability or consistency across jurisdiction and time. Further, there is no necessary link between the fire inspection outcome and any likelihood that arson charges would have been laid by a police force as a result of the suspicious nature of the fire. Whilst this is not a necessary limitation of the study, it does make it difficult to directly compare the results with previous research that has used a police-based definition for arson (such as Powell 2017, who found no link between arson-for-profit and the economic crash of 2007). In addition, as this dataset is not linked to police records, it includes only the fire location, which may be different than the home location of the vehicle owner. While this study furthers understanding of the location of fire events themselves, access to the home address of the registered vehicle could reveal interesting spatial patterns as well. Future research should explore this important activity node individually, as well as in spatial relation to the site of the fire event.

Although there is clear indication of a link between the suspicious vehicle fires analyzed within this study and the economy, potentially indicating owner-involved arson with the goal of escaping debt, it is not known what other types of suspicious fires might have been included in the data. Merrall and Chenery (2005) identified at least two other types of vehicle arson: (a) vehicles that were genuinely stolen (as opposed to insurance fraud) and destroyed by the car thieves, and (b) vehicles abandoned/disposed through arson (to avoid the costs associated with legitimate disposal). It is highly likely that both of these alternative types of suspicious fires could be included in the data analyzed here: there was no way of determining this based on the available fire incident data. If this data includes other types of suspicious fires, however, it would arguably have added noise to the economic model and weakened the overall results between the timing of suspicious vehicle fires and economic conditions, so this does not detract from the main findings. Finally, there was also no vehicle theft data available at the same temporal interval for the matching time period and it was not known the extent to which the cars involved also had related insurance claims or outstanding debt. Future 
work would be required to examine the significance of these factors.

This study relied on the DA as the spatial unit of analysis, and aggregated fire events based on the DA in which they occurred. While this is the smallest area for which socio-economic census data is consistently available, this spatial scale presents a limitation in that a number of these areas are large enough to contain hotspots of both non-suspicious and suspicious events. For example, a number of DAs that are intersected by major commuting routes display a concentration of non-suspicious fires, as expected-such routine, high-traffic routes are more likely to be the site of accidents and vehicle malfunctions. However, some of the same DAs are predominantly industrial or agricultural areas and also display a concentration of suspicious fire events. This concentration also fits an opportunity-based explanation because these sites offer limited guardianship; in addition, such relatively secluded locations can be a rational choice for arson events through a perceived lower risk of apprehension. Future work will conduct a micro-level spatio-temporal analysis at the road network level to develop a more refined picture of where and when these events occur within these dual hot spot DAs. Such a micro-level analysis can further facilitate the development of a non-suspicious and suspicious fire spatial and temporal profile, which may be used to better understand and categorize the large portion of fires recorded as having unknown 'act or omission' origins and contribute to future prevention efforts targeted towards suspicious vehicle fires.

\section{Conclusion}

This paper adds to the growing literature that demonstrates clear value in the application of opportunitybased theories of crime to fire prevention. This paper also contributes to understanding of the relationship between high-level economic factors and individual rational choices to offend: extending the framework of 'reward' to include escaping debt. These results should be of interest to police, fire services, by-laws enforcement divisions, and insurance agencies, and it would be beneficial to replicate this approach in other contexts to test the consistency of the patterns demonstrated here and extend the analysis to address some of the limitations of this attempt. It is the authors' hope that these findings can continue to drive down vehicle fires, reducing demands on already-stretched fire and emergency services, minimizing the likelihood of injury/death when responding to fires, and enhancing community safety.

\section{Abbreviations}

BC: British Columbia, Canada; DA: Canadian Census dissemination area; $\mathrm{H}$ : hypothesis.
Acknowledgements

The authors would like to acknowledge the feedback provided by three peer reviewers.

\section{Authors' contributions}

This manuscript builds on an Honours thesis produced by the lead author, HK. The article has been reshaped by authors JC and KW, with both JC, KW and HK undertaking additional statistical analysis. Author LG provided expert input from the industry perspective. Authors HK and LG helped edit the final version of the paper. All authors read and approved the final manuscript.

\section{Funding}

There was no funding involved with this research.

\section{Availability of data and materials}

The fire service data involved in this analysis is operational data belonging to Surrey Fire Services $(\mathrm{BC})$ and as such will not be shared unless specifically required.

\section{Competing interests}

The authors declare that they have no competing interests.

\section{Author details}

${ }^{1}$ Murdoch University, 90 South Street, Murdoch, WA 6051, Australia. ${ }^{2}$ The University of Western Australia, M253, 35 Stirling Highway, Perth, WA 6009, Australia. ${ }^{3}$ Portland State University, 506 SW Mill Street, Portland, OR 97201, USA. ${ }^{4}$ University of the Fraser Valley, 33844 King Road, Abbotsford, BC V2S 7M8, Canada.

Received: 27 April 2019 Accepted: 16 August 2019

Published online: 30 August 2019

\section{References}

Ackerman, W. V., \& Murray, A. T. (2004). Assessing spatial patterns of crime in Lima, Ohio. Cities, 21(5), 423-437.

Andresen, M. A. (2013). Unemployment, business cycles, crime, and the Canadian provinces. Journal of Criminal Justice, 41(4), 220-227.

Andresen, M. A. (2016). An area-based nonparametric spatial point pattern test: The test, its applications, and the future. Methodological Innovations, 9, 2059799116630659.

Andresen, M. A., \& Malleson, N. (2013). Crime seasonality and its variations across space. Applied Geography, 43, 25-35. https://doi.org/10.1016/j. apgeog.2013.06.007.

Andresen, M. A., Wuschke, K., Kinney, J. B., Brantingham, P. J., \& Brantingham, P. L. (2009). Cartograms, crime and location quotients. Crime Patterns and Analysis, 2(1), 31-46.

Asgary, A., Ghaffari, A., \& Levy, J. (2010). Spatial and temporal analyses of structural fire incidents and their causes: A case of Toronto, Canada. Fire Safety Journal, 24, 44-57.

Bernasco, W. (2008). Them again?: Same-offender involvement in repeat and near repeat burglaries. European Journal of Criminology, 5(4), 411-431.

Brantingham, P. J., \& Brantingham, P. L. (1991). Environmental criminology (2nd ed.). Prospect Heights: Waveland Press Inc.

Brantingham, P. L., \& Brantingham, P. J. (1993). Environment, routine, and situation: Toward a pattern theory of crime. In R. V. Clarke \& M. Felson (Eds.), Routine activity and rational choice (pp. 259-294). New Jersey: Transaction Publishers.

Brantingham, P. L., \& Brantingham, P. J. (2008). The rules of crime pattern theory. In R. Wortley \& L. Mazerolle (Eds.), Environmental criminology and crime analysis. Devon: Willan Publishing.

Chiricos, T. G. (1987). Rates of crime and unemployment: An analysis of aggregate research evidence. Social Problems, 34(2), 187-212.

Clare, J., Garis, L., Plecas, D., \& Jennings, C. (2012). Reduced frequency and severity of residential fires following delivery of fire prevention education by on-duty fire fighters: Cluster randomised controlled study. Journal of Safety Research, 43(123), 128.

Clare, J., Townsley, M., Birks, D. J., \& Garis, L. (2017). Patterns of police, fire, and ambulance calls-for-service: Scanning the spatio-temporal intersection of 
emergency service problems. Policing: A Journal of Policy and Practice. https ://doi.org/10.1093/police/pax038.

Clarke, R. V. (2008). Situational crime prevention. In R. Wortley \& L. Mazerolle (Eds.), Environmental criminology and crime analysis (pp. 178-194). Cullompton: Willan Publishing.

Cohen, L. E., \& Felson, M. (1979). Social change and crime rate trends: A routine activity approach. American Sociological Review, 44, 588-605.

Cohn, E. G., \& Rotton, J. (2000). Weather, seasonal trends and property crimes in minneapolis, 1987-1988: A moderator-variable time-series analysis of routine activities. Journal of Environmental Psychology, 20, 257-272.

Corcoran, J., Higgs, G., Brunsdon, C., Ware, A., \& Norman, P. (2010). The use of spatial analytical techniques to explore patterns of fire incidence: A South Wales case study. Computers, Environment and Urban Systems, 31, 623-647.

Corcoran, J., Higgs, G., \& Higginson, A. (2011). Fire incidence in metropolitan areas: A comparative study of Brisbane (Australia) and Cardiff (United Kingdom). Applied Geography, 31, 65-75.

Cornish, D., \& Clarke, R. V. (2008). The rational choice perspective. In R. Wortley \& L. Mazerolle (Eds.), Environmental Criminology and Crime Analysis (pp. 21-47). Cullompton, UK: Willan Publishing.

Devery, C., Jochelson, R., \& Nguyen da Huong, M. T. (1993). Patterns of motor vehicle theft. Sydney: NSW Bureau of Crime Statistics and Research.

Dionne, G., \& Wang, K. C. (2013). Does insurance fraud in automobile theft insurance fluctuate with the busines cycle? Journal of Risk and Uncertainty, 47(1), $67-92$.

Eck, J. E. (2015). Who should prevent crime at places? The advantages of regulating place managers and challenges to police services. Policing: A Journal of Policy and Practice, 9(3), 223-233.

Eriksen, M. D., \& Carson, J. M. (2017). A burning question: Does arson increase when local house prices decline? Journal of Risk and Insurance, 84(1), 7-34

Felson, M., \& Poulsen, E. (2003). Simple indicators of crime by time of day. International Journal of Forecasting, 19, 595-601.

Goebel, P. R., \& Harrison, D. M. (2012). Money to burn: Economic incentives and the incidence of arson. Journal of Housing Research, 21(1), 49-65.

Groff, E., \& McCord, E. S. (2012). The role of neighbourhood parks as crime generators. Security Journal, 25(1), 1-24.

Grubb, J. A., \& Nobles, M. R. (2016). A spatio temporal analysis of arson. Journal of Research in Crime and Delinquency, 53(1), 66-92. https://doi. org/10.1177/0022427815590858.

Haberman, C. P., Sorg, E. T., \& Ratcliffe, J. H. (2017). Assessing the validity of the law of crime concentration across different temporal scales. Journal of Quantitative Criminology, 33, 547-567. https://doi.org/10.1007/s10940-016-9327-4.

Harries, K. (2006). Extreme spatial variatons in crime density in Baltimore County, MD. Geoforum, 37, 404-416.

Johnson, S. D. (2008). Repeat burglary victimization: A tale of two theories. Journal of Experimental Criminology, 184, 215-240.

Jones, G., \& Kutan, A. M. (2004). Volatile interest rates, volatile crime rates: A new argument for interest rates smoothing. Ann Arbor: William Davidson Inst.

Kinney, J. B., Brantingham, P. L., Wuschke, K., Kirk, M. G., \& Brantingham, P. J. (2008). Crime attractors, generators and detractors: Land use and urban crime opportunities. Built Environment, 34(1), 62.

Landau, S. F., \& Fridman, D. (1993). The seasonality of violent crime: The case of robbery and homicide in Israel. Journal of Research in Crime and Delinquency, 30, 163-191.

Leclerc, B. (2017). Crime scripts. In R. Wortley \& M. Townsley (Eds.), Environmental criminology and crime analysis (pp. 119-141). Cullopton: Willan Publishing.

Martinez, N. N., Lee, Y., Eck, J. E., \& SooHyun, O. (2017). Ravenous wolves revisited: A systematic review of offending concentration. Crime Science. https://doi. org/10.1186/s40163-017-0072-2.

Merrall, S., \& Chenery, S. (2005). Vehicle fires: Explaining the rise in vehicle fires. Retrieved from www.lefigaro.fr/assets/pdf/ARSONVEHICLEUK.pdf. Accessed April 2019.

Milner, A. J., Niven, H., \& LaMontagne, A. D. (2015). Occupational class differences in suicide: Evidence of changes over time and during the global financial crisis in Australia. BMC Psychiatry, 15(1), 223.

Newton, A., \& Felson, M. (2015). Editorial: Crime patterns in time and space: The dynamics of crime opportunities in urban areas. Crime Science. https://doi. org/10.1186/s40163-015-0025-6

Perry, J. D., \& Simpson, M. E. (1987). Violent crimes in a city: Environmental determinants. Environment and Behavior, 19(1), 77-90.

Potter, R. (2000). Arson on the increase: Motor vehicle theft and arson in South Australia. Retrieved from www.researchgate.net/publication/228357172_Arson
_on_the_increase_Motor_vehicle_theft_and_arson_in_South_Australia. Accessed April 2019.

Powell, Z. A. (2017). Burnin' down the house: The 2007 recession and the effect on arson. Deviant Behavior, 39(5), 541-553. https://doi.org/10.1080/01639 625.2016.1269554.

Powell, Z. A., Grubb, J. A., \& Nobles, M. R. (2019). A near repeat examination of economic crimes. Crime \& Delinquency, 65(9), 1319-1340. https://doi. org/10.1177/0011128718811927.

Ratcliffe, J. H. (2002). Aoristic signatures and the spatio-temporal analysis of high volume crime patterns. Journal of Quantitative Criminology, 18(1), 23-43.

Rosenfeld, R., \& Fornango, R. (2007). The impact of economic conditions on robbery and property crime: The role of consumer sentiment. Criminology, 45(4), 735-769.

Seals, A., \& Nunley, J. (2007). The effects of inflation and demographic change on property crime: A structural time series approach. Department of Economics and Finance Working Paper Series. Middle Tennessee State University, Murfreesboro, TN.

Sidebottom, A., Belur, J., Bowers, K., Tompson, L., \& Johnson, S. D. (2011). Theft in price-volatile markets: On the relationship between copper price and copper theft. Journal of Research in Crime and Delinquency, 48(3), 396-418. https ://doi.org/10.1177/0022427810393021.

Simpson, S. (1996). Resource allocation by measures of relative social need in geographical areas: The relevance of the signed Chi squared, the percentage, and the raw count. Environment and Planning A, 28, 537-554.

Smith, M. D., Devine, J. A., \& Sheley, J. F. (1992). Crime and unemployment: Effects across age and race categories. Sociological Perspectives, 35(4), 551-572.

SooHyun, O., Martinez, N. N., Lee, Y., \& Eck, J. E. (2017). How concentrated is crime among victims? A systematic review from 1977 to 2014. Crime Science. https ://doi.org/10.1186/s40163-017-0071-3.

Statistics Canada. (2015). Census dictionary: Dissemination area. Retrieved from https://www12.statcan.gc.ca/census-recensement/2011/ref/dict/geo02 1-eng.cfm. Accessed April 2019.

Statistics Canada. (2017). Focus on Geography Series, 2016 Census. Retrieved from Ottawa, Ontario, Data products, 2016 Census: https://www12 .statcan.gc.ca/census-recensement/2016/as-sa/fogs-spg/Facts-csd-eng. cfm?LANG=Eng\&GK=CSD\&GC=5915004. Accessed April 2019.

Statistics Canada. (2019a). Real-time Canadian socio-economic information management (CANSIM) tables. Retrieved from https://www.statcan.gc.ca/ eng/dai/btd/rct. Accessed April 2019.

Statistics Canada. (2019b). Surveys and statistical programs: Labour force survey. Retrieved from http://www23.statcan.gc.ca/imdb/p2SV.pl?Function=getSu rvey\&SDDS=3701. Accessed April 2019.

Townsley, M., Homel, R., \& Chaseling, J. (2003). Infectious burglaries: A test of the near repeat hypothesis. British Journal of Criminology, 43, 615-633.

Turchan, B., Grubb, J. A., Pizarro, J. M., \& McGarrell, E. F. (2018). Arson in an urban setting: A multi-event near repeat chain analysis in Flint, Michigan. Security Journal. https://doi.org/10.1057/s41284-018-0155-0.

United Nations Office on Drugs and Crime. (2011). Monitoring the impact of economic crisis on crime. Retrieved from www.unodc.org/documents/dataandanalysis/statistics/crime/GIVAS_Final_Report.pdf. Accessed April 2019.

United States Department of Transportation. (2009). Summary of travel trends: 2009 National Household Travel Survey. Retrieved from https://nhts.ornl. gov/2009/pub/stt.pdf. Accessed April 2019.

United States Fire Administration. (2014). Vehicle arson - a combustible crime: National arson awareness week media kit. Retrieved from https://www.usfa. fema.gov/downloads/pdf/arson/aaw14_media_kit.pdf. Accessed April 2019.

Weisburd, D. (2015). The law of crime concentration and the criminology of place - the 2014 Sutherland Address. Criminology, 53(2), 133-157. https://doi. org/10.1111/1745-9125.12070.

Wuschke, K., Clare, J., \& Garis, L. (2013). Temporal and geographic clustering of residential structure fires: A theoretical platform for targeted fire prevention. Fire Safety Journal, 62, 3-12.

Yearwood, D. L., \& Koinis, G. (2011). Revisiting property crime and economic conditions: An exploratory study to identify predictive indicators beyond unemployment rates. The Social Science Journal, 48(1), 145-158.

\section{Publisher's Note}

Springer Nature remains neutral with regard to jurisdictional claims in published maps and institutional affiliations. 